Article

\title{
Eco-Innovation in Circular Agri-Business
}

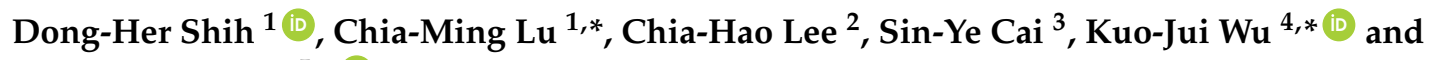 \\ Ming-Lang Tseng ${ }^{5, *}$ (i) \\ 1 Department of Information Management, National Yunlin University of Science and Technology, \\ Douliu 64002, Taiwan; shihdh@yuntech.edu.tw \\ 2 Department of Finance, MingDao University, Changhua County 52345, Taiwan; lijiahao@mdu.edu.tw \\ 3 Department of Information Management, Lunghwa University of Science \& Technology, Taoyuan 33306, \\ Taiwan; Wendy611232002@gmail.com \\ 4 School of Business, Dalian University of Technology, Panjing 124221, China \\ 5 Institute of Innovation and Circular Economy, Asia University, Taichung 41354, Taiwan \\ * Correspondence: joe@jiahsing.com.tw (C.-M.L.); wukuojui@dlut.edu.cn (K.-J.W.); \\ tsengminglang@gmail.com (M.-L.T.); Tel.: +886-910-459-836 (C.-M.L.); +86-138-0427-6853 (K.-J.W.); \\ +886-910-309-400 (M.-L.T.)
}

Received: 20 February 2018; Accepted: 7 April 2018; Published: 10 April 2018

\begin{abstract}
This study constructs a theory of eco-innovation in circular agri-business. Although previous studies have discussed eco-innovation in circular agri-business, they did not address eco-innovation from the perspective of a closed-loop sustainable supply chain. Hence, this study applied the fuzzy TOPSIS method to conduct the analysis and determine the interrelationship between eco-innovation and the closed-loop concept. The results are consistent with the theory and a significant improvement in terms of the decisive attributes. The findings suggest that improving water management, relationships with suppliers, knowledge sharing, environmental management systems, and new product and service development are the most effective and efficient ways to build eco-innovation in circular agri-business. The managerial and theoretical implications are discussed.
\end{abstract}

Keywords: eco-innovation; fuzzy TOPSIS; circular agri-business; closed-loop supply chains

\section{Introduction}

The theme of eco-innovation has received substantial attention in academic research and policy circles. Eco-innovations are a subset of and share many characteristics with innovations in the economy [1]. Eco-innovation is defined as innovation related to the environment, greening or sustainability that aims for a more sustainable environment by improving ecology [2]. Thus, eco-innovation can improve products, services and processes to promote sustainable development. Given significant global challenges such as the economic recession, environmental degradation and resource shortages, eco-innovation offers a path to addressing the most pressing economic and environmental issues and helping industry achieve sustainability. Due to increased mass production and improved technological efficiency, eco-innovation must address aspects of the economy, ecology and society to impose limitations on the present rate of environmental resource use [1]. Therefore, improving eco-innovation is receiving much attention. To offer an efficient way to improve eco-innovation, an analysis that constructs a set of measurements to determine the eco-innovation practices that are critical for improvement is necessary.

In a previous study, Xavier et al. [3] emphasized that eco-innovation may include the development and introduction of new products/services, market exploration, systems redesign and broad ecological dimensions in economic strategies. Accordingly, eco-innovation provides both environmental and economic benefits, resulting in a win-win situation. For consumers and society at large, eco-innovation 
reduces the burden on the environment. Therefore, understanding the features and specifics of eco-innovation processes is critical to managing these processes more efficiently because more sustainable markets are on the rise [2]. Several models have been proposed to achieve a greater understanding of the dynamics or structure of eco-innovation and to facilitate the integration and implementation of eco-innovation processes in a firm. To determine precise guidelines, an analysis that assesses the relationships among the attributes and identifies the decisive ones for improvement is necessary.

However, previous studies have shown that effectively realizing emission reductions and remanufacturing have become the dominant tendencies in the sustainable economy [4]. Bhattacharyya et al. [5] found a growing interest in the recovery of raw materials from used products collected from customers as an alternative to the conventional metal extraction processes. Realizing the significant impact to the environment, several consumer and non-profit organizations in developing countries in Asia are encouraging the adoption of industrial ecology through the recovery of waste via recycling and reuse by means of the closed-loop supply chain [6]. Although eco-innovation is often considered vital to decreasing the burden on the environment, and sustainability is accepted as an important aspect of competitiveness, few studies analyze the value of eco-innovation and sustainability in a closed-loop supply chain. Hence, the following research questions are proposed:

- What are the decisive attributes of eco-innovation?

- What are the decisive attributes that affect the development of circular agri-business?

This study attempts to apply fuzzy TOPSIS techniques to approach these goals, which are beyond experts' opinions. This method allows the integration of qualitative and quantitative criteria into decision-making processes. The remainder of this study is organized as follows. Section 2 offers a review and discussion of the relevant literature with regard to eco-innovation and circular agri-business. Section 3 describes the data sampling and the proposed method. Section 4 provides the case information and analytical results. Section 5 addresses several managerial and theoretical implications. Concluding remarks and possible future studies are included in the final section.

\section{Literature Review}

Eco-innovation, closed-loop sustainable supply chain management, the proposed method and the proposed measures are addressed in this section.

\subsection{Eco-Innovation}

Eco-innovation refers to innovative activities that promote a sustainable environment by improving ecology. Due to increased mass production, eco-innovation must draw on aspects of the economy, ecology, and society to impose limitations on the present state of environmental resource use [2]. Hojnik et al. [7] explored the interrelationship between internationalization and firms' economic performance by investigating the mediating effect of eco-innovation. Moreover, prior studies have focused on discovering whether eco-innovation should be adopted and integrated in firm-level strategies to improve economic performance. A prior study documented that exporting firms are more innovative than non-exporting firms [7]. Therefore, eco-innovation can provide a boost to firm-level economic performance. Based on the organizational learning perspective, the authors developed a step-by-step argument for the mediated effect of internationalization on firm performance [7].

Eco-innovation activities consist of enhanced operational processes, products/services and organizational practices that decrease or prevent negative impacts of the environment [8]. In fact, eco-innovation exerts a significant influence on environmental performance and competitiveness. Tseng and Bui [9] proposed a series of measures and a hybrid method to assess eco-innovation in industrial symbiosis. The results revealed that eco-innovation enhances a firm's competitive advantage, and industrial symbiosis allows firms to achieve a win-win situation in their supply chain network. Eco-innovation thus has positive effects on the environment and economic performance. Their study 
concluded that eco-innovation has emerged as a driver of the development of an environmental orientation in the supply chain. However, they did not study eco-innovation in circular agri-business.

Dewick and Foster [10] studied how focal drivers promote eco-innovation in consumption and production systems. They combined studies of innovation and sustainable supply chains to determine how firms may attain system-wide sustainability. Eco-innovation can improve environmental and economic performance simultaneously, in contrast to environmental innovation and conventional innovation [11]. Innovation is an important mechanism driven by the continuous need for quality improvement. For this reason, studies in the field of eco-innovation have been abundant from different research perspectives and have gained interest from different disciplines. Other fields that support the interdisciplinary study of eco-innovation are ecological economics and ecology. Ecological economics addresses the relationships between ecosystems and economic systems by integrating ecological, social and economic aspects in sustainable development. This concept has been evidenced in industrial ecology, which enhances material efficiency and energy flows within a regional industrial system [2].

\subsection{Closed-Loop Sustainable Supply Chain Management}

Shaharudin et al. [6] studied the closed-loop supply chain, which consists of both forward and reverse activities in a specific system and includes economic, environmental and social aspects. To address both the forward and reverse chains simultaneously, the closed-loop supply chain is considered to play a critical role in the management domain [12]. Because it relates to sustainable supply chain management in the context of the existence of numerous environmental issues, the closed-loop supply chain is currently receiving considerable attention. The closed-loop concept involves the integration of supply chain activities required to ensure flows and materials are circular and products are consumed without any waste after their use [13]. Instead, products are disassembled, reused, remanufactured or recycled into a source of raw materials [14].

The closed-loop supply chain concentrates mainly on the recycling and remanufacturing of products. It is one of the most prudent approaches toward sustainability and long-term business continuity and survival [5]. At present, the focus is primarily on the economic aspects through the assessment of recognized best practices. Huang and Wang [15] applied the Stackelberg game to obtain the balance within a closed-loop supply chain and analyzed the impact of remanufacturing ability on performance based on remanufacturing technology licensing. Chen et al. [16] presented a two-stage closed-loop supply chain model that considered the uncertainty in the market size, the return capacity and the quality of recycling. Although closed-loop supply chain decision models were developed in the abovementioned literature, no empirical studies investigating eco-innovation in closed-loop supply chain management have been conducted [4].

\subsection{Proposed Measures}

Existing studies have proposed several attributes. These attributes are presented as four aspects and 15 criteria, as shown in Table 1. The four aspects include environmental technologies (AS1), organizational innovations (AS2), green product and service innovations (AS3), and green innovation processes (AS4).

Table 1. Proposed aspects and criteria.

\begin{tabular}{ccc}
\hline Aspect & & Criteria \\
\hline & C1 & Waste management \\
Environmental & C2 & C3 \\
technologies (AS1) & C4 & Recycle, reduce, reuse \\
& C5 & Environmental monitoring \\
& C6 & Pollution controls \\
\hline Organizational & C7 & Management of the value chain \\
innovations (AS2) & C8 & Information knowledge sharing \\
& C9 & Creating knowledge \\
& & Implementation of environmental management system
\end{tabular}


Table 1. Cont.

\begin{tabular}{ccc}
\hline Aspect & & Criteria \\
\hline $\begin{array}{c}\text { Green product and } \\
\text { service innovations }\end{array}$ & C10 & Development of environmentally friendly new products and services \\
(AS3) & C12 & Eco-efficient package innovation \\
Green innovation & C13 & Adapting to customers through personalization \\
process (AS4) & C14 & Kesearch and development related to green innovation processes \\
& C15 & Cooperation with suppliers \\
\hline
\end{tabular}

According to Jabbour [25] and Kuehr [26], environmental technology involves developing hardware and software by adopting new design principles, operational tools and processes along with practices for continuously improving environmental performance. Waste management (C1) reduces the amount of materials, energy, water, and land used, thereby raising the input efficiency of each agri-business unit that is produced and distributed [17,18]. Green power technology development (C2) is the development of new technology that is more environmentally friendly [19]. Recycle-reduce-reuse (C3) allows used resources and used materials to be part of the production and consumption process for a longer time, that is, until they are physically degraded. Following Horbach et al. [17], pollution controls (C5) are an important type of eco-innovation that can lower air emissions and waste. In addition, environmental monitoring (C4) can help to reduce damage by preparing methods against risks.

Organizational innovation is a necessary precondition for innovation to be fully implemented and exploited [27]. Gunday et al. [28] found that structural improvement was affected by organizational innovation, which enhanced inter-organizational cooperation and collaboration. These in turn generated an appropriate environment for the adoption of process innovation. Organizational innovation includes four criteria: value chain management (C6); information knowledge sharing (C7); knowledge creation (C8), and; the implementation of an environmental management system (C9). Value chain management (C6) includes strengthening the transformation from local and unidimensional optimization to extensive life cycle optimization and addresses the entire product life cycle [19]. Information knowledge sharing (C7) allows suppliers, manufacturers and retailers to increase the accuracy of forecasts, orchestrate production and delivery, align inventory-related decisions and develop a platform to share information [9]. Tseng and Bui [9] noted the importance of creating knowledge, which is related to the sources of knowledge, and suggested that the key to success relies on collaboration and coordination among partners throughout the entire value chain. Finally, Ociepa-Kubicka and Pachura [19] discussed the implementation of an environmental management system (C9), suggesting that eco-innovation occurs only if the applications are not harmful to human health and the public widely understands the meaning of the natural environment.

Green product and service innovations include three criteria. The development of environmentally friendly new products and services (C10) generates new demand and opportunities for green product/service deliverables [20]. Tietze and Hansen [21] discussed eco-efficient package innovation (C11). Traditional and non-sustainable business practices encounter constraints linked to a rising green agenda; current products/services deliverables are thus required to consider a broader definition of value to fulfill public expectations, including ecological value. Subsequently, adapting to customers by offering personalization (C12) can be considered a buffer to reconfigure and shift existing products/services and design new products/services as ecological product/service deliverables, thereby addressing stakeholders' needs and market segments. This approach is a value proposition that complements the more "traditional" financial and market-related metrics [19].

The green innovation process includes three criteria. Knowledge sharing among partners/employees (C13) means that a firm is able to promote knowledge sharing practices among groups or organizations to generate new ideas and explore new business opportunities to facilitate innovative activities [22]. With respect to research and development in the context of green innovation processes (C14), Goldbach et al. [24] indicated that cooperation with suppliers (C15) can guarantee inputs or elements 
with eco-friendly characteristics. These inputs may not be available in the current market, thus requiring verification until requirements are met. Otherwise, the internal production process must be modified. Thus, this study proposes four aspects and 15 criteria to explore the decisive attributes that assist agri-business in reaching the circular level.

\section{Method}

\subsection{Proposed Method}

Prior studies have studied many aspects of eco-innovation. Xavier et al. [2] applied theoretical and conceptual research to systematically review the literature on eco-innovation models. Hojnik et al. [7] studied the role of eco-innovation and addressed the adoption and integration of eco-innovation into firm-level strategies to improve economic performance via the common-method variance. Hojnik and Ruzzier [1] employed a quantitative research methodology and focused on the diffusion stage of eco-innovation to discover what drives eco-innovation. Gunday et al. [28] used the common-method variance based on empirical data to study the effects of innovation types on firm performance. Tseng and Bui [9] employed the fuzzy Delphi method to identify the key eco-innovation attributes for enhancing industrial symbiosis performance.

The fuzzy TOPSIS method is an efficient method for determining the difficulties in each sector and to rank suppliers. TOPSIS has been successfully applied in different study areas. For example, Kannan et al. [29] proposed a framework using fuzzy TOPSIS to construct a decision model for Brazilian electronics firms with regard to a green supplier. Gupta and Barua [30] studied supplier selection among small- and medium-sized firms based on their green innovation abilities using fuzzy TOPSIS. Lee et al. [31] developed a new procedure that combined the Delphi method with the fuzzy TOPSIS technique for flood risk and vulnerability management. Therefore, this study uses the fuzzy TOPSIS technique to examine the relationships among eco-innovation criteria in a closed-loop sustainable supply chain.

\subsection{Fuzzy TOPSIS}

Fuzzy set theory is used to transfer linguistic preferences into a fuzzy scale for further analysis. TOPSIS is the most commonly used technique for solving multi-criteria decision making (MCDM) problems and was proposed by Hwang and Yoon [32]. TOPSIS adopts the concept of geometric distance to consider the alternatives based on positive (shortest distance) and negative (longest distance) solutions [33]. The choice of the fuzzy TOPSIS technique in this case study is justified by several reasons. The approach has the advantages of changes in alternatives, changes in criteria, agility in the decision process, quantity of criteria and alternatives [34]. This method is applied to compare a set of alternatives by weights, normalizing scores for the criteria and then calculating the geometric distance between each alternative. The fuzzy TOPSIS steps are as follows:

1. An assessment matrix is generated consisting of $x$ alternatives and $y$ criteria, where the intersection of each alternative and criterion is given by $a_{i j}$. It can be rewritten as $\left[a_{i j}\right]_{x \times y}$ and then $a_{i j}=\left(\ell_{i j}, m_{i j}, r_{i j}\right)$.

2. These transferred fuzzy numbers are normalized through the equation $\bar{\ell}_{i j}=\left[\ell_{i j}-\min \left(\ell_{i j}\right)\right] /$ $\max \left(r_{i j}\right)-\min \left(\ell_{i j}\right), \bar{m}_{i j}=\left[m_{i j}-\min \left(m_{i j}\right)\right] / \max \left(r_{i j}\right)-\min \left(\ell_{i j}\right), \bar{r}_{i j}=\left[r_{i j}-\min \left(r_{i j}\right)\right] /$ $\max \left(r_{i j}\right)-\min \left(\ell_{i j}\right)$.

3. The normalized value $s_{i j}=\bar{m}_{i j} /\left(1+\bar{m}_{i j}-\bar{\ell}_{i j}\right)$ and $p_{i j}=\bar{r}_{i j} /\left(1+\bar{r}_{i j}-\bar{m}_{i j}\right)$ are generated and then utilized to attain the total normalized crisp value $n_{i j}=\left[s_{i j}\left(1-s_{i j}\right)+\left(p_{i j}\right)^{2}\right] /\left(1-s_{i j}+p_{i j}\right)$.

4. The crisp value is mapped in matrix $N=\left[n_{i j}\right]_{x \times y^{\prime}}$ and the following equation is used to normalize the matrix: $\bar{n}_{i j}=n_{i j} / \sum_{i=1}^{x}\left(n_{i j}\right), j=1,2, \cdots, y$. 
5. The weighted normalized decision matrix $t_{i j}=\bar{n}_{i j} \times \omega_{i}, i=1,2, \cdots, x ; j=1,2, \cdots, y$ is computed, where $\omega_{i}=\omega_{i j} / \sum_{j=1}^{y} \omega_{i j}, i=1,2, \cdots, x$, and $\omega_{i}$ must satisfy $\sum_{i=1}^{x} \omega_{i}=1$.

6. The worst $A_{w}$ and best alternative $A_{b}$ are identified by adopting the following equations:

$$
\begin{aligned}
& A_{w}=\left\{\left(\min _{j} t_{i j} \mid j \in W\right),\left(\max _{j} v_{i j} \mid j \in B\right)\right\}, i=1,2, \cdots x=\left\{t_{j}^{w} \mid j=1,2, \cdots, y\right\} \\
& A_{b}=\left\{\left(\max _{j} v_{i j} \mid j \in W\right),\left(\min _{j} v_{i j} \mid j \in B\right)\right\}, i=1,2, \cdots x=\left\{t_{j}^{b} \mid j=1,2, \cdots, y\right\}
\end{aligned}
$$

where $W=\{1,2, \cdots, x\}$ indicates that criteria have a negative effect, while $B=\{1,2, \cdots, x\}$ indicates that criteria have a positive effect.

7. The distance between alternative $x$ under the worst situation and alternative $x$ under the best situation is calculated as follows:

$$
\begin{gathered}
\alpha_{i}=\sqrt{\sum_{j=1}^{y}\left(t_{i j}-t_{j}^{w}\right)^{2}}, i=1,2, \cdots, x \\
\beta_{i}=\sqrt{\sum_{j=1}^{y}\left(t_{i j}-t_{j}^{b}\right)^{2}}, i=1,2, \cdots, x
\end{gathered}
$$

where $\alpha_{i}$ and $\beta_{i}$ represent the L2-norm distance under the worst and best situation, respectively.

8. The following equation becomes similar to the worst situation:

$$
\gamma_{i}=\alpha_{i} /\left(\alpha_{i}+\beta_{i}\right), 0 \leq \gamma_{i} \leq 1, i=1,2, \cdots, x
$$

where $\gamma_{i}=1$ means that the alternative solution has the best situation; otherwise, the alternative has the worst situation. The alternatives based on the value of $\gamma_{i}, i=1,2, \cdots, x$ are ranked.

\subsection{Proposed Analytical Procedures}

1. Purifying the proposed aspects and criteria: the collected aspects and criteria are reviewed by seven experts to confirm their congruence in reflecting the real problem. These seven experts include two professors, one CEO, one vice president and three senior managers who have at least ten years of experience working in agri-business.

\begin{tabular}{|c|c|c|c|c|c|c|}
\hline \multirow{2}{*}{$\begin{array}{c}\text { Linguistic Preference } \\
\text { Unimportant }\end{array}$} & \multicolumn{3}{|c|}{ Criteria } & \multicolumn{3}{|c|}{ Aspects } \\
\hline & 0.0 & 0.1 & 0.3 & 0 & 1 & 3 \\
\hline Less important & 0.1 & 0.3 & 0.5 & 1 & 3 & 5 \\
\hline Important & 0.3 & 0.5 & 0.7 & 3 & 5 & 7 \\
\hline Moderately important & 0.5 & 0.7 & 0.9 & 5 & 7 & 9 \\
\hline Very important & 0.7 & 0.9 & 1.0 & 7 & 9 & 10 \\
\hline
\end{tabular}

2. Transferring the responses: once the proposed aspects and criteria are confirmed, the survey instrument is developed and distributed to experts to assess its performance. These assessments are stated in the linguistic scale by adopting steps 1-3 to gather crisp values (in contrast to Table 2).

Table 2. Fuzzy linguistics for aspects and criteria.

3. Generating the weighted normalized matrix: these transformation values must be defuzzed, step 4 is used to normalize the matrix. Then, step 5 generates the weighted normalized matrix.

4. Obtaining the worst and best alternatives: the weighted normalized matrix takes the equations in step 6 to individually attain the worst and best alternatives.

5. Calculating the distance between the worst and best alternatives: employing the Euclidean metric and adopting the equations in step 7 determine the distance. 
6. Ranking the aspects: finally, applying step 8 ranks the aspects. The ranking offers a precise guideline to improve agri-business and eco-innovation performance in a closed-loop sustainable supply chain.

\section{Results}

\subsection{Industrial Background}

Agri-business continues to play a critical role in Vietnam's change to a market-based economy. Agri-business represents $22 \%$ of gross domestic product (GDP), $30 \%$ of exports and $60 \%$ of employment. This explains why companies are taking environmental responsibility beyond their boundaries to reduce waste and prevent pollution. Companies have started to recognize the extension of their green practices, such as the strategy for waste minimization and green technologies, in the upper and lower streams of their supply chain [35]. Realizing the significant impact on the environment, several consumer organizations and non-governmental organizations (NGOs) in developing countries in Asia are encouraging the adoption of industrial ecology through the recovery of waste via recycling and reuse by means of the closed-loop system approach [36]. Therefore, this study was conducted to help Vietnamese agri-business industry managers learn more about the attributes that drive the industry's supply chain.

Agri-business has been facing a growing number of environmental issues, including solid waste and water and air pollution. Modern agri-business practices started the process of agri-business pollution. This process causes the degradation of the ecosystem, land, and environment due to the by-products of agri-business. However, eco-innovation can enhance environmental awareness and increase operating efficiency within a firm. Hence, this study provides an appropriate context for studying eco-innovation in circular agri-business. The fuzzy TOPSIS approach was applied to highlight the significant role of eco-innovation in circular agri-business [37].

\subsection{Analytical Results}

1. Following the proposed analytical procedure, experts' assessments are transferred from linguistic preferences to fuzzy scales via a contrast, as shown in Table 2, by employing procedures 1 and 2 . Then, the transferred fuzzy matrix is shown in Table 3.

Table 3. Transformation of the criteria assessments of seven experts.

\begin{tabular}{ccccccccccccccccccccccc}
\hline & \multicolumn{3}{c}{ Expert 1 } & \multicolumn{3}{c}{ Expert 2 } & \multicolumn{3}{c}{ Expert 3 } & \multicolumn{3}{c}{ Expert 4 } & \multicolumn{3}{c}{ Expert 5 } & \multicolumn{3}{c}{ Expert 6 } \\
\hline C1 & 0.5 & 0.7 & 0.9 & 0.7 & 0.9 & 1 & 0.3 & 0.5 & 0.7 & 0.5 & 0.7 & 0.9 & 0.7 & 0.9 & 1 & 0.5 & 0.7 & 0.9 & 0.7 & 0.9 & 1 \\
C2 & 0.3 & 0.5 & 0.7 & 0.3 & 0.5 & 0.7 & 0.5 & 0.7 & 0.9 & 0.5 & 0.7 & 0.9 & 0.7 & 0.9 & 1 & 0.7 & 0.9 & 1 & 0.5 & 0.7 & 0.9 \\
C3 & 0.1 & 0.3 & 0.5 & 0.3 & 0.5 & 0.7 & 0.5 & 0.7 & 0.9 & 0.7 & 0.9 & 1 & 0.1 & 0.3 & 0.5 & 0.5 & 0.7 & 0.9 & 0.3 & 0.5 & 0.7 \\
C4 & 0.7 & 0.9 & 1 & 0.7 & 0.9 & 1 & 0.7 & 0.9 & 1 & 0.5 & 0.7 & 0.9 & 0.3 & 0.5 & 0.7 & 0.1 & 0.3 & 0.5 & 0.3 & 0.5 & 0.7 \\
C5 & 0.5 & 0.7 & 0.9 & 0.3 & 0.5 & 0.7 & 0.7 & 0.9 & 1 & 0.7 & 0.9 & 1 & 0.5 & 0.7 & 0.9 & 0.5 & 0.7 & 0.9 & 0.5 & 0.7 & 0.9 \\
C6 & 0.3 & 0.5 & 0.7 & 0.5 & 0.7 & 0.9 & 0.3 & 0.5 & 0.7 & 0.3 & 0.5 & 0.7 & 0.5 & 0.7 & 0.9 & 0.7 & 0.9 & 1 & 0.5 & 0.7 & 0.9 \\
C7 & 0.7 & 0.9 & 1 & 0.7 & 0.9 & 1 & 0.5 & 0.7 & 0.9 & 0.5 & 0.7 & 0.9 & 0.3 & 0.5 & 0.7 & 0.3 & 0.5 & 0.7 & 0.3 & 0.5 & 0.7 \\
C8 & 0.1 & 0.3 & 0.5 & 0.7 & 0.9 & 1 & 0.7 & 0.9 & 1 & 0.5 & 0.7 & 0.9 & 0.3 & 0.5 & 0.7 & 0.1 & 0.3 & 0.5 & 0.5 & 0.7 & 0.9 \\
C9 & 0.5 & 0.7 & 0.9 & 0.1 & 0.3 & 0.5 & 0.5 & 0.7 & 0.9 & 0.5 & 0.7 & 0.9 & 0.3 & 0.5 & 0.7 & 0.3 & 0.5 & 0.7 & 0.7 & 0.9 & 1 \\
C10 & 0.7 & 0.9 & 1 & 0.3 & 0.5 & 0.7 & 0.5 & 0.7 & 0.9 & 0.5 & 0.7 & 0.9 & 0.7 & 0.9 & 1 & 0.7 & 0.9 & 1 & 0.5 & 0.7 & 0.9 \\
C11 & 0.3 & 0.5 & 0.7 & 0.7 & 0.9 & 1 & 0.3 & 0.5 & 0.7 & 0.3 & 0.5 & 0.7 & 0.7 & 0.9 & 1 & 0.3 & 0.5 & 0.7 & 0.5 & 0.7 & 0.9 \\
C12 & 0.7 & 0.9 & 1 & 0.5 & 0.7 & 0.9 & 0.7 & 0.9 & 1 & 0.7 & 0.9 & 1 & 0.7 & 0.9 & 1 & 0.1 & 0.3 & 0.5 & 0.7 & 0.9 & 1 \\
C13 & 0.1 & 0.3 & 0.5 & 0.7 & 0.9 & 1 & 0.3 & 0.5 & 0.7 & 0.1 & 0.3 & 0.5 & 0.3 & 0.5 & 0.7 & 0.5 & 0.7 & 0.9 & 0.5 & 0.7 & 0.9 \\
C14 & 0.7 & 0.9 & 1 & 0.5 & 0.7 & 0.9 & 0.5 & 0.7 & 0.9 & 0.3 & 0.5 & 0.7 & 0.1 & 0.3 & 0.5 & 0.7 & 0.9 & 1 & 0.7 & 0.9 & 1 \\
C15 & 0.3 & 0.5 & 0.7 & 0.7 & 0.9 & 1 & 0.5 & 0.7 & 0.9 & 0.3 & 0.5 & 0.7 & 0.7 & 0.9 & 1 & 0.7 & 0.9 & 1 & 0.1 & 0.3 & 0.5 \\
\hline
\end{tabular}

2. Applying procedure 3 normalizes the values and yields the ranking of the criteria and normalized weights, as shown in Table 4 . Table 5 shows that the fuzzy decision matrix is associated with all weights among the aspects and criteria. 
Table 4. Fuzzy importance weights and rankings.

\begin{tabular}{ccccccc}
\hline Criteria & & Weight & & $\gamma_{i}$ & Rank & Normalized Weight \\
\hline C1 & 0.390 & 0.757 & 0.914 & 1.857 & 1 & 0.168 \\
C2 & 0.500 & 0.700 & 0.871 & 0.690 & 5 & 0.063 \\
C3 & 0.357 & 0.557 & 0.743 & 0.552 & 15 & 0.05 \\
C4 & 0.471 & 0.671 & 0.829 & 0.657 & 8 & 0.06 \\
C5 & 0.529 & 0.729 & 0.900 & 0.719 & 4 & 0.065 \\
C6 & 0.443 & 0.643 & 0.829 & 0.638 & 10 & 0.058 \\
C7 & 0.471 & 0.671 & 0.843 & 0.662 & 7 & 0.06 \\
C8 & 0.414 & 0.614 & 0.786 & 0.605 & 13 & 0.055 \\
C9 & 0.414 & 0.614 & 0.800 & 0.610 & 12 & 0.055 \\
C10 & 0.557 & 0.757 & 0.914 & 0.743 & 3 & 0.067 \\
C11 & 0.443 & 0.643 & 0.814 & 0.633 & 11 & 0.057 \\
C12 & 0.586 & 0.786 & 0.914 & 0.762 & 2 & 0.069 \\
C13 & 0.357 & 0.557 & 0.743 & 0.552 & 14 & 0.05 \\
C14 & 0.500 & 0.700 & 0.857 & 0.686 & 6 & 0.062 \\
C15 & 0.471 & 0.671 & 0.829 & 0.657 & 8 & 0.06 \\
\hline
\end{tabular}

Table 5. Fuzzy decision matrix.

\begin{tabular}{lllllllllllll}
\hline & \multicolumn{3}{c}{ AS1 } & \multicolumn{3}{c}{ AS2 } & \multicolumn{3}{c}{ AS3 } & & AS4 \\
\hline C1 & 2.714 & 4.714 & 6.714 & 4.714 & 6.714 & 8.429 & 5.000 & 7.000 & 8.571 & 4.429 & 6.429 & 8.000 \\
C2 & 4.429 & 6.429 & 8.000 & 4.714 & 6.714 & 8.429 & 2.714 & 4.714 & 6.714 & 3.286 & 5.286 & 7.143 \\
C3 & 5.286 & 7.286 & 8.857 & 3.000 & 5.000 & 6.857 & 3.571 & 5.571 & 7.429 & 3.571 & 5.571 & 7.429 \\
C4 & 3.857 & 5.857 & 7.714 & 4.143 & 6.143 & 7.857 & 3.000 & 5.000 & 6.857 & 3.571 & 5.571 & 7.286 \\
C5 & 3.571 & 5.571 & 7.571 & 3.857 & 5.857 & 7.857 & 4.429 & 6.429 & 8.143 & 5.286 & 7.286 & 9.000 \\
C6 & 3.286 & 5.286 & 7.143 & 4.143 & 6.143 & 7.857 & 5.286 & 7.286 & 8.857 & 5.000 & 7.000 & 8.714 \\
C7 & 4.714 & 6.714 & 8.286 & 3.571 & 5.571 & 7.286 & 5.000 & 7.000 & 8.571 & 5.000 & 7.000 & 8.714 \\
C8 & 4.143 & 6.143 & 7.857 & 5.571 & 7.571 & 9.143 & 3.571 & 5.571 & 7.429 & 2.714 & 4.714 & 6.714 \\
C9 & 3.571 & 5.571 & 7.429 & 3.857 & 5.857 & 7.714 & 3.571 & 5.571 & 7.286 & 4.429 & 6.429 & 8.143 \\
C10 & 5.000 & 7.000 & 8.714 & 4.143 & 6.143 & 7.714 & 3.571 & 5.571 & 7.286 & 4.143 & 6.143 & 7.857 \\
C11 & 3.857 & 5.857 & 7.857 & 4.143 & 5.857 & 7.857 & 3.571 & 5.571 & 7.286 & 4.714 & 6.714 & 8.286 \\
C12 & 4.429 & 6.429 & 8.286 & 3.857 & 5.857 & 7.571 & 4.143 & 6.143 & 7.857 & 3.286 & 5.286 & 7.143 \\
C13 & 4.429 & 6.429 & 8.143 & 3.286 & 5.286 & 7.143 & 3.571 & 5.571 & 7.286 & 4.143 & 6.143 & 7.857 \\
C14 & 4.714 & 6.714 & 8.286 & 4.143 & 6.143 & 7.857 & 5.000 & 7.000 & 8.571 & 4.143 & 6.143 & 7.857 \\
C15 & 3.286 & 5.286 & 7.000 & 4.143 & 6.143 & 7.857 & 5.286 & 7.286 & 8.857 & 4.429 & 6.429 & 8.143 \\
\hline
\end{tabular}

3. Following procedure 4 generates the fuzzy normalized decision matrix, as shown in Table 6. However, experts' assessments of aspects (contrasting with Table 2) must be considered in the matrix. Thus, Table 7 presents the fuzzy weighted normalized decision matrix.

Table 6. Fuzzy normalized decision matrix.

\begin{tabular}{ccccccccccccc}
\hline & \multicolumn{3}{c}{ AS1 } & \multicolumn{3}{c}{ AS2 } & \multicolumn{3}{c}{ AS3 } & \multicolumn{3}{c}{ AS4 } \\
\hline C1 & 0.306 & 0.532 & 0.758 & 0.516 & 0.734 & 0.922 & 0.565 & 0.79 & 0.968 & 0.492 & 0.714 & 0.889 \\
C2 & 0.500 & 0.726 & 0.903 & 0.516 & 0.734 & 0.922 & 0.306 & 0.532 & 0.758 & 0.365 & 0.587 & 0.794 \\
C3 & 0.597 & 0.823 & 1.000 & 0.328 & 0.547 & 0.75 & 0.403 & 0.629 & 0.839 & 0.397 & 0.619 & 0.825 \\
C4 & 0.435 & 0.661 & 0.871 & 0.453 & 0.672 & 0.859 & 0.339 & 0.565 & 0.774 & 0.397 & 0.619 & 0.81 \\
C5 & 0.403 & 0.629 & 0.855 & 0.422 & 0.641 & 0.859 & 0.500 & 0.726 & 0.919 & 0.587 & 0.810 & 1.000 \\
C6 & 0.371 & 0.597 & 0.806 & 0.453 & 0.672 & 0.859 & 0.597 & 0.823 & 1.000 & 0.556 & 0.778 & 0.968 \\
C7 & 0.532 & 0.758 & 0.935 & 0.391 & 0.609 & 0.797 & 0.565 & 0.79 & 0.968 & 0.556 & 0.778 & 0.968 \\
C8 & 0.468 & 0.694 & 0.887 & 0.609 & 0.828 & 1.000 & 0.403 & 0.629 & 0.839 & 0.302 & 0.524 & 0.746 \\
C9 & 0.403 & 0.629 & 0.839 & 0.422 & 0.641 & 0.844 & 0.403 & 0.629 & 0.823 & 0.492 & 0.714 & 0.905 \\
C10 & 0.565 & 0.79 & 0.984 & 0.453 & 0.672 & 0.844 & 0.403 & 0.629 & 0.823 & 0.46 & 0.683 & 0.873 \\
C11 & 0.435 & 0.661 & 0.887 & 0.453 & 0.641 & 0.859 & 0.403 & 0.629 & 0.823 & 0.524 & 0.746 & 0.921 \\
C12 & 0.500 & 0.726 & 0.935 & 0.422 & 0.641 & 0.828 & 0.468 & 0.694 & 0.887 & 0.365 & 0.587 & 0.794 \\
C13 & 0.500 & 0.726 & 0.919 & 0.359 & 0.578 & 0.781 & 0.403 & 0.629 & 0.823 & 0.46 & 0.683 & 0.873 \\
C14 & 0.532 & 0.758 & 0.935 & 0.453 & 0.672 & 0.859 & 0.565 & 0.79 & 0.968 & 0.46 & 0.683 & 0.873 \\
C15 & 0.371 & 0.597 & 0.79 & 0.453 & 0.672 & 0.859 & 0.597 & 0.823 & 1.000 & 0.492 & 0.714 & 0.905 \\
\hline
\end{tabular}


Table 7. Fuzzy weighted normalized decision matrix.

\begin{tabular}{llllllllllllll}
\hline & \multicolumn{3}{c}{ AS1 } & \multicolumn{3}{c}{ AS2 } & \multicolumn{3}{c}{ AS3 } & \multicolumn{3}{c}{ AS4 } \\
\hline C1 & 0.306 & 0.532 & 0.758 & 0.516 & 0.734 & 0.922 & 0.565 & 0.79 & 0.968 & 0.492 & 0.714 & 0.889 \\
C2 & 0.500 & 0.726 & 0.903 & 0.516 & 0.734 & 0.922 & 0.306 & 0.532 & 0.758 & 0.365 & 0.587 & 0.794 \\
C3 & 0.597 & 0.823 & 1.000 & 0.328 & 0.547 & 0.750 & 0.403 & 0.629 & 0.839 & 0.397 & 0.619 & 0.825 \\
C4 & 0.435 & 0.661 & 0.871 & 0.453 & 0.672 & 0.859 & 0.339 & 0.565 & 0.774 & 0.397 & 0.619 & 0.810 \\
C5 & 0.403 & 0.629 & 0.855 & 0.422 & 0.641 & 0.859 & 0.500 & 0.726 & 0.919 & 0.587 & 0.810 & 1.000 \\
C6 & 0.371 & 0.597 & 0.806 & 0.453 & 0.672 & 0.859 & 0.597 & 0.823 & 1.000 & 0.556 & 0.778 & 0.968 \\
C7 & 0.532 & 0.758 & 0.935 & 0.391 & 0.609 & 0.797 & 0.565 & 0.790 & 0.968 & 0.556 & 0.778 & 0.968 \\
C8 & 0.468 & 0.694 & 0.887 & 0.609 & 0.828 & 1.000 & 0.403 & 0.629 & 0.839 & 0.302 & 0.524 & 0.746 \\
C9 & 0.403 & 0.629 & 0.839 & 0.422 & 0.641 & 0.844 & 0.403 & 0.629 & 0.823 & 0.492 & 0.714 & 0.905 \\
C10 & 0.565 & 0.790 & 0.984 & 0.453 & 0.672 & 0.844 & 0.403 & 0.629 & 0.823 & 0.460 & 0.683 & 0.873 \\
C11 & 0.435 & 0.661 & 0.887 & 0.453 & 0.641 & 0.859 & 0.403 & 0.629 & 0.823 & 0.524 & 0.746 & 0.921 \\
C12 & 0.500 & 0.726 & 0.935 & 0.422 & 0.641 & 0.828 & 0.468 & 0.694 & 0.887 & 0.365 & 0.587 & 0.794 \\
C13 & 0.500 & 0.726 & 0.919 & 0.359 & 0.578 & 0.781 & 0.403 & 0.629 & 0.823 & 0.460 & 0.683 & 0.873 \\
C14 & 0.532 & 0.758 & 0.935 & 0.453 & 0.672 & 0.859 & 0.565 & 0.790 & 0.968 & 0.46 & 0.683 & 0.873 \\
C15 & 0.371 & 0.597 & 0.79 & 0.453 & 0.672 & 0.859 & 0.597 & 0.823 & 1.000 & 0.492 & 0.714 & 0.905 \\
\hline
\end{tabular}

4. Finally, following procedures 5 and 6 identifies the worst and best conditions for providing the basis for ranking the aspects, as shown in Table 8. Therein, AS4 is most affected by eco-innovation performance, followed by AS1, AS3 and AS2.

Table 8. Aspect ranking.

\begin{tabular}{ccccc}
\hline & $\alpha_{i}$ & $\beta_{i}$ & $\gamma_{i}$ & Ranking \\
\hline AS1 & 6.584 & 20.318 & 0.755 & 2 \\
AS2 & 13.357 & 18.899 & 0.586 & 4 \\
AS3 & 6.583 & 20.242 & 0.755 & 3 \\
AS4 & 6.401 & 19.942 & 0.757 & 1 \\
\hline
\end{tabular}

\section{Implications}

Theoretical and managerial implications are discussed in this section.

\subsection{Theoretical Implications}

The results show that green innovation processes (AS4) have the largest effect on building eco-innovation when considering a closed-loop sustainable supply chain. Eco-innovation changes people's values and the sustainability of their lifestyle through green innovation processes [2]. Moreover, knowledge sharing is found to have a direct and positive association with green innovation processes and a positive impact on the development of eco-innovation by firms [38]. In addition, green innovation processes are alternatives to production and consumption that involve knowledge sharing among partners or employees, green innovation process research and development, and cooperation with suppliers [39]. Therefore, a very strong direct relationship between green innovation processes and eco-innovation is created. Creating an effective process in terms of green innovation is considered the most efficient way to protect firms' competitive advantages in the industry and improve overall firm sustainability.

This study provides empirical evidence that environmental technologies (AS1) are another critical aspect in achieving successful eco-innovation. The positive relationship between the environmental technologies aspect of eco-innovation and the three perspectives of sustainability (economic, social, and environmental) was also emphasized in a prior study [40]. Eco-innovative technologies have been commonly applied for many years in numerous firms around the world to minimize environmental costs [19]. Waste management, pollution control, environmental monitoring, green power technology development, and recycle-reduce-reuse control are criteria associated with eco-innovation that focus on environmental technologies [2]. Developing or applying technologies that are environmentally friendly 
has a significant impact on increasing firms' financial benefits. Hence, these technologies enhance a firm's sustainability. However, a vicious cycle appears as new technologies emerge. These technologies are often not adopted because they are too expensive, and they are often too expensive because they are not adopted [41]. Therefore, the success of eco-innovation can be achieved by financial support.

In conclusion, this study identifies two important attributes of eco-innovation to gain better insight into the theoretical implications of this concept. Therein, green innovation processes (AS4) and environmental technologies (AS1) are the two most important attributes and should receive priority in enhancing the importance of eco-innovation. By focusing on the importance of eco-innovation, firms can become increasingly sustainable.

\subsection{Managerial Implications}

Waste management (C1) is the most important criterion underlying eco-innovation in circular agri-business. It is a process in which waste is treated, stored, transported, and disposed to reduce pollution, recycle useful materials, and create more green energy. Managing waste in a proper way helps to protect human health and the environment and enhances a firm's sustainability. Therefore, it is suggested that firms should create a program that controls the amount of waste they generate. The relevant managers should receive details and accurate data regarding how, when, and where waste is treated and any data regarding the volume and transport of waste. By analyzing all the information, firms can compare recycling rates each month and change their waste management plan to be more effective. Furthermore, knowledge about waste management should be disseminated by each member of the board of directors to every employee in the firm to have the most effective results.

Cooperation with suppliers (C15) plays a vital role in formulating a firm's innovative ability. The relationship between firms and suppliers should be built based on trust, mutual respect, information exchange, technological collaboration, and investment. In this way, firms can provide customers in a timely manner with products and services that are desirable in every aspect, including quality, price, and environmental impact. Furthermore, suitable environmental standards and policies should be formulated based on a strong agreement between firms and suppliers, which helps to avoid conflicts about material requirements between firms and suppliers, enhance the sustainability of both parties, and deliver the best eco-products and services to customers.

Information knowledge sharing (C7) among buyers, manufacturers, and suppliers is an essential criterion for a firm to achieve success. Firms gain numerous benefits from information knowledge sharing, such as improving communication among employees, enabling better and faster decision-making processes, stimulating innovation and growth, improving deliveries to customers, and reducing the loss of knowledge. Hence, it is suggested that firms in circular agri-business pay more attention to enhancing information knowledge sharing to increase work efficiency and effectiveness. By building a tracking system for products, firms can make more accurate forecasts or decisions based on all information regarding the stock, delivery, and condition of products. Furthermore, workshops, training courses, or seminars should also be organized to share information among co-workers and strengthen relationships among them.

An environmental management system provides a framework that helps firms achieve their environmental performance goals. Such a system can help achieve cost savings, improve operational efficiency and environmental performance, increase customer loyalty, and enhance employees' skills. Therefore, the implementation of an environmental management system (C9) plays a critical role in eco-innovation in circular agri-business. This system should follow the generic requirements of ISO 14001, which establishes a common reference for firms in terms of communicating about environmental management to customers, regulators, the public, and other stakeholders. Hence, firms should give more consideration to launching environmental management systems to enhance profitability.

The development of environmentally friendly new products and services (C10) improves eco-innovation. The perspective of eco-innovation includes both economics (quality, costs, and delivery) and ecology (global warming prevention, resource recycling, and environmental consciousness). 
Firms should implement research and development processes to create new products and services that meet environmental policy standards. For circular agri-businesses in this study, the creation of environmentally friendly new products and services also means enhancing human life and the natural environment. Therefore, firms are encouraged to pay more attention to developing increasingly more environmentally friendly products and services, which is critical to building eco-innovation and to gaining further competitive advantages over business rivals.

The five driving criteria mentioned above are the managerial implications obtained from this study. There has been a lack of key criteria related to eco-innovation in circular agri-business in previous studies. Improving waste management (C1), cooperating with suppliers (C15), sharing information knowledge (C7), implementing environmental management systems (C9), and developing environmentally friendly new products and services (C10) are considered the most effective and efficient ways to build eco-innovation in circular agri-business.

\section{Conclusions}

Eco-innovation and circular agri-business are two main streams of study that have rapidly developed over the past few years. However, no study has addressed the link between these two topics. To fill this gap, this study adopted the TOPSIS method, which is a practical and useful technique for ranking, selecting, and comparing alternatives. In addition, the proposed aspects and criteria were ranked by groups of experienced experts. Environmental technologies, organizational innovations, green product and service innovations, and green innovation processes are the four main aspects, which are expanded into 15 criteria. The results also show that the top five criteria support the set of measurements and contribute to the industry.

The findings indicate that the implementation of environmental management systems plays an important role in building eco-innovation in circular agri-business. This study also extends the understanding in the literature by showing the critical attributes that should be focused on in the implementation of eco-innovation. To enhance eco-innovation in closed-loop supply chain management, all eco-innovation practices must be improved and successfully implemented within the firm strategies of green innovation processes and environmental technologies. Moreover, from the environmental technologies aspect, knowledge sharing among partners/employees, green innovation process research and development, and cooperation with suppliers were also found to be critical criteria for enhancing circular agri-business.

The contribution of this study is to explore the decisive attributes of eco-innovation while considering the closed-loop supply chain. We found that the most important criterion in eco-innovation in a closed-loop agri-business is waste management (C1). Additionally, cooperation with suppliers (C15) has a large contribution in firms because a good relationship with suppliers is very important in business development. Information sharing (C7) is an integral part of business. Environmental management systems (C9) and environmentally friendly product and service development (C10) are the best methods to improve eco-innovation in circular agri-business.

This study has several limitations. First, it was conducted based on the eco-innovation and closed-loop sustainable supply chain literature to determine the relationship between proposed aspects and criteria. Therefore, this series of aspects and criteria might not be comprehensive in terms of addressing the problem. Second, the sample collection focused only on eco-innovation in a closed-loop sustainable supply chain. Hence, external generalizability is limited. Future studies should use the data in multiple frameworks to obtain better results with generalizability. Moreover, the selected aspects need to have quantitative method support in order to avoid the subjective. Exploratory factor analysis, clustering and interpretive structural modeling assist us in structuring the aspects with objective considerations.

Acknowledgments: This study was supported by the National Natural Science Foundation of China (71701029) and the Liaoning Academy of Social Sciences Fund (L17BGL019) and Fundamental Research Funds for the Central Universities (DUT16RC (3)038). We thank the following for their data collection and efforts on this 
manuscript: Luong Quoc Tuan, Phan Thuy Duong, Nguyen Tan Minh, Chau My Ngo, Mai Nguyen Xuan Tri, and Do Thuy Hong. We are grateful for the efforts of the anonymous reviewers and editors.

Author Contributions: Dong-Her Shih and Chia-Ming Lu proposed the idea of this study; Chia-Hao Lee and Sin-Ye Cai performed the data transformation and wrote the program codes; Kuo-Jui Wu and Ming-Lang Tseng drafted the paper and improved the method for solving the research problems.

Conflicts of Interest: The authors declare no conflict of interest.

\section{References}

1. Hojnik, J.; Ruzzier, M. What drives eco-innovation? A review of an emerging literature. Environ. Innov. Soc. Transit. 2016, 19, 31-41. [CrossRef]

2. Xavier, A.F.; Naveiro, R.M.; Aoussat, A.; Reyes, T. Systematic literature review of eco-innovation models: Opportunities and recommendations for future research. J. Clean. Prod. 2017, 149, 1278-1302. [CrossRef]

3. Xavier, A.F.; Naveiro, R.M.; Aoussat, A. The Eco-Innovation Concepts through a Strategic Perspective. In Proceedings of the IAMOT 2015 International Association for Management of Technology Conference, Cape Town, South Africa, 8-11 June 2015; pp. 2275-2293.

4. $\mathrm{Xu}, \mathrm{L}$.; Wang, C. Sustainable manufacturing in a closed-loop supply chain considering emission reduction and remanufacturing. Resour. Conserv. Recycl. 2018, 131, 297-304. [CrossRef]

5. Bhattacharyya, S.; Choudhary, A.; Shankar, R. A decision model for a strategic closed-loop supply chain to reclaim End-of-Life Vehicles. Int. J. Prod. Econ. 2018, 195, 273-286.

6. Shaharudin, M.R.; Govindan, K.; Zailani, S.; Tan, K.C.; Iranmanesh, M. Product return management: Linking product returns, closed-loop supply chain activities and the effectiveness of the reverse supply chains. J. Clean. Prod. 2017, 149, 1144-1156. [CrossRef]

7. Hojnik, J.; Ruzzier, M.; Manolova, T.S. Internationalization and economic performance: The mediating role of eco-innovation. J. Clean. Prod. 2018, 171, 1312-1323. [CrossRef]

8. Dong, Y.; Wang, X.; Jin, J.; Qiao, Y.; Shi, L. Effects of eco-innovation typology on its performance: Empirical evidence from Chinese enterprises. J. Eng. Technol. Manag. 2014, 34, 78-98. [CrossRef]

9. Tseng, M.-L.; Bui, T.-D. Identifying eco-innovation in industrial symbiosis under linguistic preferences: A novel hierarchical approach. J. Clean. Prod. 2017, 140, 1376-1389. [CrossRef]

10. Dewick, P.; Foster, C. Focal organisations and eco-innovation in consumption and production systems. Ecol. Econ. 2018, 143, 161-169. [CrossRef]

11. Ghisetti, C.; Pontoni, F. Investigating policy and R\&D effects on environmental innovation: A meta-analysis. Ecol. Econ. 2015, 118, 57-66.

12. Tahoori, G.; Rosnah, M.Y.; Norzima, Z. Key issues and challenges of a sustainable closed loop supply chain. Appl. Mech. Mater. 2014, 564, 684-688. [CrossRef]

13. Guide, V.D.R.; Harrison, T.P.; Van Wassenhove, L.N. The challenge of closed-loop supply chains. Interfaces 2003, 33, 3-6. [CrossRef]

14. Hassini, E.; Surti, C.; Searcy, C. A literature review and a case study of sustainable supply chains with a focus on metrics. Int. J. Prod. Econ. 2012, 140, 69-82. [CrossRef]

15. Huang, Y.; Wang, Z. Closed-loop supply chain models with product take-back and hybrid remanufacturing under technology licensing. J. Clean. Prod. 2017, 142, 3917-3927. [CrossRef]

16. Chen, J.; Cheng, J.; Dai, S. Regional eco-innovation in China: An analysis of eco-innovation levels and influencing factors. J. Clean. Prod. 2017, 153,1-14. [CrossRef]

17. Horbach, J.; Rammer, C.; Rennings, K. Determinants of eco-innovations by type of environmental impact-The role of regulatory push/pull, technology push and market pull. Ecol. Econ. 2012, 78, 112-122. [CrossRef]

18. Rennings, K.; Ziegler, A.; Ankele, K.; Hoffmann, E. The influence of different characteristics of the EU environmental management and auditing scheme on technical environmental innovations and economic performance. Ecol. Econ. 2006, 57, 45-59. [CrossRef]

19. Ociepa-Kubicka, A.; Pachura, P. Eco-innovations in the functioning of companies. Environ. Res. 2017, 156, 284-290. [CrossRef] [PubMed]

20. Williams, A. Product service systems in the automobile industry: Contribution to system innovation? J. Clean. Prod. 2007, 15, 1093-1103. [CrossRef] 
21. Tietze, F.; Hansen, E.G. To own or to use: How product service systems impact firms' innovation behaviour. Eur. Financ. Rev. 2013, 53-56.

22. Lundvall, B.Å.; Nielsen, P. Knowledge management and innovation performance. Int. J. Manpow. 2007, 28, 207-223. [CrossRef]

23. Tsai, K.-H.; Wang, J.-C. External technology sourcing and innovation performance in LMT sectors: An analysis based on the Taiwanese Technological Innovation Survey. Res. Policy 2009, 38, 518-526. [CrossRef]

24. Goldbach, M.; Seuring, S.; Back, S. Co-ordinating sustainable cotton chains for the mass market. Greener Manag. Int. 2003, 2003, 65-78. [CrossRef]

25. Jabbour, C.J.C. In the eye of the storm: Exploring the introduction of environmental issues in the production function in Brazilian companies. Int. J. Prod. Res. 2010, 48, 6315-6339. [CrossRef]

26. Kuehr, R. Environmental technologies-from misleading interpretations to an operational categorisation \& definition. J. Clean. Prod. 2007, 15, 1316-1320.

27. Lam, A. Organizational innovation. In The Oxford Handbook of Innovation; Fagerberg, J., Mowery, D.C., Nelson, R.R., Eds.; Oxford University Press: Oxford, UK, 2005; pp. 115-147.

28. Gunday, G.; Ulusoy, G.; Kilic, K.; Alpkan, L. Effects of innovation types on firm performance. Int. J. Prod. Econ. 2011, 133, 662-676. [CrossRef]

29. Kannan, D.; Jabbour, A.B.L.S.; Jabbour, C.J.C. Selecting green suppliers based on GSCM practices: Using fuzzy TOPSIS applied to a Brazilian electronics company. Eur. J. Oper. Res. 2014, 233, 432-447. [CrossRef]

30. Gupta, H.; Barua, M.K. Supplier selection among SMEs on the basis of their green innovation ability using BWM and fuzzy TOPSIS. J. Clean. Prod. 2017, 152, 242-258. [CrossRef]

31. Lee, C.K.M.; Ching Yeung, Y.; Hong, Z. An integrated framework for outsourcing risk management. Ind. Manag. Data Syst. 2012, 112, 541-558. [CrossRef]

32. Hwang, C.L.; Yoon, K. Methods for multiple attribute decision making. In Multiple Attribute Decision Making Lecture Notes in Economics and Mathematical Systems; Springer: Berlin/Heidelberg, Germany, 1981; Volume 186, pp. 58-191.

33. Assari, A.; Mahesh, T.M.; Assari, E. Role of public participation in sustainability of historical city: Usage of TOPSIS method. Indian J. Sci. Technol. 2012, 5, 2289-2294.

34. Junior, F.R.L.; Osiro, L.; Carpinetti, L.C.R. A comparison between Fuzzy AHP and Fuzzy TOPSIS methods to supplier selection. Appl. Soft Comput. 2014, 21, 194-209. [CrossRef]

35. Sarkis, J. Greening the Supply Chain; Springer Science \& Business Media: London, UK, 2006.

36. Hsu, C.C.; Choon Tan, K.; Hanim Mohamad Zailani, S.; Jayaraman, V. Supply chain drivers that foster the development of green initiatives in an emerging economy. Int. J. Oper. Prod. Manag. 2013, 33, 656-688. [CrossRef]

37. Scarpellini, S.; Valero-Gil, J.; Portillo-Tarragona, P. The "economic-finance interface" for eco-innovation projects. Int. J. Proj. Manag. 2016, 34, 1012-1025. [CrossRef]

38. Wong, S.K.S. Environmental requirements, knowledge sharing and green innovation: Empirical evidence from the electronics industry in China. Bus. Strategy Environ. 2013, 22, 321-338. [CrossRef]

39. Pacheco, D.A.D.J.; Ten Caten, C.S.; Jung, C.F.; Ribeiro, J.L.D.; Navas, H.V.G.; Cruz-Machado, V.A. Eco-innovation determinants in manufacturing SMEs: Systematic review and research directions. J. Clean. Prod. 2017, 142, 2277-2287. [CrossRef]

40. Sánchez-Medina, P.S.; Corbett, J.; Toledo-López, A. Environmental innovation and sustainability in small handicraft businesses in Mexico. Sustainability 2011, 3, 984-1002. [CrossRef]

41. Tamayo-Orbegozo, U.; Vicente-Molina, M.-A.; Villarreal-Larrinaga, O. Eco-innovation strategic model. A multiple-case study from a highly eco-innovative European region. J. Clean. Prod. 2017, 142, 1347-1367. [CrossRef]

(C) 2018 by the authors. Licensee MDPI, Basel, Switzerland. This article is an open access article distributed under the terms and conditions of the Creative Commons Attribution (CC BY) license (http:/ / creativecommons.org/licenses/by/4.0/). 